\title{
Spontaneous Tumor Lysis Syndrome
}

\author{
Wiebke Wesemüller ${ }^{a} \quad$ Christian Taverna ${ }^{b}$

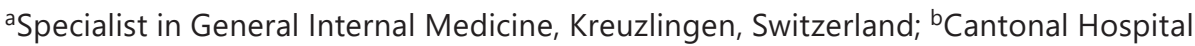 \\ Münsterlingen, Münsterlingen, Switzerland
}

\section{Keywords}

Acute renal failure · Hyperkalemia $\cdot$ Hyperuricemia - Oncological emergency · Spontaneous tumor lysis syndrome

\begin{abstract}
Tumor lysis syndrome (TLS) is a hemato-oncological emergency characterized by metabolic and electrolyte imbalances which are associated with disintegrating tumor cells. The syndrome is frequently observed when starting cytotoxic treatment of hematological malignancies, while the incidence of spontaneous tumor lysis prior to the start of tumor therapy is rare. Here, we present a case of spontaneous TLS in a male patient who was referred with unspecific symptoms and suspected metastatic malignancy. He developed acute renal failure before the diagnosis of a high-grade B-cell lymphoma (double hit lymphoma) and start of therapy. Although the course of TLS would have required intensive care, the patient rejected such treatment for personal reasons and died soon after the discontinuation of therapy. The case emphasizes the life-saving relevance of early detection and appropriate treatment of TLS. It also demonstrates the importance of actively screening for TLS, primarily in patients with malignant diseases and high tumor load, even if they are not receiving cytotoxic therapy.
\end{abstract}

(C) 2020 The Author(s).

Published by S. Karger AG, Basel

\section{Introduction}

Tumor lysis syndrome (TLS) is a hemato-oncological emergency [1-4]. It results from rapid lysis of malignant cells, which leads to the immediate release of various intracellular cell components (uric acid, potassium, and phosphate) [5]. The syndrome is typically associated with the development of hyperuricemia, hyperkalemia, and hyperphosphatemia with subsequent hypokalemia. These electrolyte imbalances cause life-threatening organ 
Fig. 1. Image showing abdominal tumor mass prior to initating therapy (FDG-PET-CT). Figure reprinted with kind permission of Thomas Kelly, Senior Physician Nuclear Medicine, Cantonal Hospital Münsterlingen, Münsterlingen, Switzerland.

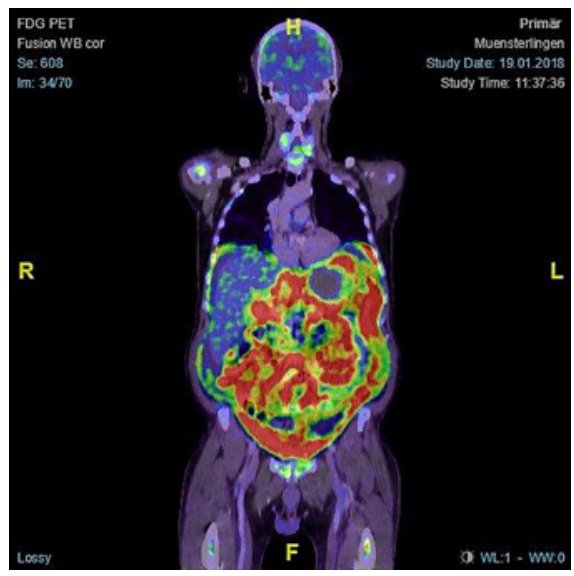

dysfunction, with acute renal failure and fatal cardiac arrhythmia among the most severe manifestations.

TLS generally occurs at the beginning of chemotherapy or immunotherapy for specific tumor entities [6]. Significant tumor-associated factors include a high tumor load, a high proliferation rate, and the chemosensitivity of the underlying disease [2, 7-9], along with clinical and individual risk factors, such as advanced age, pre-existing renal insufficiency or hyperuricemia, and reduced volume status [6]. In rare cases, TLS can also occur spontaneously [10-18]. The condition must be actively tracked in regular laboratory checks for detection.

\section{Case Report}

\section{Medical History}

A 75-year-old patient suffering from suspected metastatic malignant disease with unknown primary tumor was referred to our oncological outpatient clinic for further investigation and the initiation of an appropriate therapy. During the initial consultation, the patient described a cumulative 4-kg loss of body weight within 3 weeks with a simultaneous increase in abdominal circumference, loss of appetite, and heartburn as well as pronounced night sweats and thirst. He also reported a rapid decline of physical fitness with progressive dyspnea.

The computed tomography (CT) examination of the chest and abdomen (January 19, 2018), performed previously on an outpatient basis, had revealed the clinical picture of malignant metastatic disease with 4-quadrant ascites, peritoneal depositions, and an infiltrated omentum (PET-CT image) (Fig. 1, 2). The imaging procedures had not been able to clearly detect a primary tumor.

In the first consultation, the patient emphasized his clear preference for alternative healing methods. He strongly opposed against intensive care therapy.

In the initial examination (January 15), the patient presented in good general condition. We noted a distended abdomen with reduced bowel sounds and pain in the epigastric and right lower abdominal area.

The laboratory analysis (January 15) showed significantly elevated inflammatory parameters (C-reactive protein $66 \mathrm{mg} / \mathrm{L}$, leukocytosis $12.7 \mathrm{~g} / \mathrm{L}$ with neutrophilia) as well as an elevated creatinine level of $118 \mu \mathrm{mol} / \mathrm{L}$, a lactate dehydrogenase (LDH) value 10 times above 
Fig. 2. Image showing abdominal tumor mass prior to initating therapy (FDG-PET-CT). Figure reprinted with kind permission of Thomas Kelly, Senior Physician Nuclear Medicine, Cantonal Hospital Münsterlingen, Münsterlingen, Switzerland.

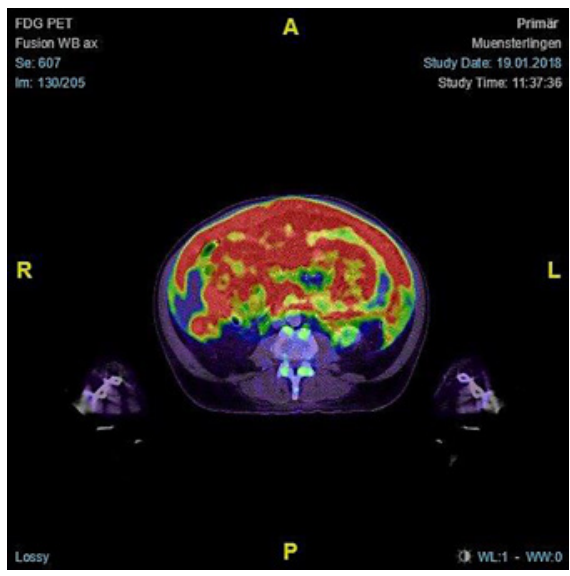

the reference value $(4,758 \mathrm{U} / \mathrm{L})$, and a uric acid value 2 times above the reference value $(738$ $\mu \mathrm{mol} / \mathrm{L})$, with all other electrolytes in the normal range.

The PET-CT examination revealed pronounced FDG depositions in the peritoneum, mesentery, and pleura with a distribution pattern comparable to primary effusion lymphoma. A CT-guided biopsy of the pleural mass (January 22) showed a high-grade B-cell lymphoma (double hit lymphoma) with a high proliferation rate Ki-67 of approximately $90 \%$.

Seven days after the first visit in our clinic, hyperkalemia, hyperphosphatemia, hypocalcemia, and hyperuricemia, as well as a further increase of creatinine ( $246 \mathrm{mmol} / \mathrm{L}), \mathrm{LDH}$, and urea occurred, in parallel to the worsening clinical condition. Accordingly, the patient met the criteria for spontaneous clinical TLS.

After repeated discussions, the patient agreed to enter the hospital. We started intravenous hydration and rasburicase and we initiated a pre-phase chemotherapy with prednisone (100 mg/day p.o.) and vincristine ( $2 \mathrm{mg}$ i.v.). The patient finally agreed to a transfer to the intensive care unit for hemodialysis.

While the patient's kidney function recovered (creatinine $134 \mathrm{mmol} / \mathrm{L}$ ) and his hyperuricemia and hyperkalemia leveled out, his overall condition deteriorated and the patient wished to go to the palliative care unit where he died a few hours later. The subsequent autopsy did not show any macroscopically or microscopically identifiable infiltrates of the previously diagnosed high-grade B-cell lymphoma.

\section{Discussion}

This is the case of 75-year-old patient with spontaneous TLS due to high-grade B-cell lymphoma with a high proliferation rate and a large tumor mass in the abdomen. TLS occurred before the initiation of chemotherapy. Being uncertain regarding therapy from the beginning, the patient finally decided to stop treatment and died in the palliative care unit. However, this leaves the question of how to improve the early detection of a TLS risk constellation to avoid TLS-related deaths.

\section{How Is TLS Defined?}

The classification and definition of TLS dates back to 2004 and is based on the CairoBishop criteria, which distinguish between laboratory TLS and clinical TLS [6, 19]. Laboratory TLS is present if at least 2 of the laboratory values for uric acid, potassium, or phosphate are

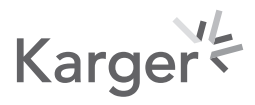




\section{Case Reports in Oncology}

Table 1. Cairo-Bishop definition of laboratory tumor lysis syndrome (TLS) $[2-4,22]$

\begin{tabular}{l|l}
\hline Case Rep Oncol 2020;13:1116-1124 \\
\hline DOI: 10.1159/000509643 & $\begin{array}{l}\text { @ 2020 The Author(s). Published by S. Karger AG, Basel } \\
\text { www.karger.com/cro }\end{array}$ \\
\hline
\end{tabular}

Wesemüller/Taverna: Tumor Lysis Syndrome

\begin{tabular}{ll}
\hline Laboratory value & Serum concentration \\
\hline Uric acid & $\geq 476 \mu \mathrm{mol} / \mathrm{L}$ or $>25 \%$ increase from baseline \\
Potassium & $\geq 6 \mathrm{mmol} / \mathrm{L}$ or $>25 \%$ increase from baseline \\
Phosphate & $\geq 1.45 \mathrm{mmol} / \mathrm{L}$ or $>25 \%$ increase from baseline \\
Calcium & $\leq 1.75 \mathrm{mmol} / \mathrm{L}$ or $>25 \%$ decrease from baseline \\
\hline
\end{tabular}

$\geq 2$ laboratory value changes or $>25 \%$ increase from baseline 3 days before or 7 days after cytotoxic therapy.

Table 2. Cairo-Bishop definition of clinical tumor lysis syndrome (TLS) [2-4, 22]

\begin{tabular}{lll}
\hline $\begin{array}{l}\text { Organ } \\
\text { dysfunction }\end{array}$ & Stage & \\
\cline { 2 - 3 } Serum & $1-3$ & $>3.0-6.0 \times$ ULN \\
creatinine & $\begin{array}{l}\text { 2: } 1.5 \times 1.5-3.0 \times \text { ULN } \\
\text { 3: }>3.0 \times \text { ULN }\end{array}$ & \\
\hline Cardiac & 1: No intervention required & Life-threatening, arrhythmias \\
arrhythmias & 2: Asymptomatic, drug intervention required & with signs of cardiac \\
& 3: Symptomatic, cannot be controlled with medication, controlled & decompensation \\
& with defibrillator & Seizures of any kind that are \\
Seizures & 1: None & prolonged, repetitive \\
& 2: Short generalized seizure, seizures controlled by medication, \\
& focal seizures & \\
\hline
\end{tabular}

Clinical TLS is defined as laboratory TLS plus $\geq 1$ organ dysfunction. Stage 4 is associated with an immediate danger to life. Stage 5 indicates death.

pathologically elevated or if a $25 \%$ increase from baseline can be documented within 3 days before or 7 days after the initiation of chemotherapy. The reverse applies to the serum values for calcium [3] (Table 1).

To meet the criteria of the more severe clinical TLS, one of the following clinical parameters must be present in addition: renal dysfunction, cardiac arrhythmia, seizures, or sudden death. There are 5 stages of severity [3] (Table 2).

\section{What Are the Causes of TLS? Which Factors Play a Role?}

In pathophysiological terms, tumor cell lysis generally occurs $12-72 \mathrm{~h}$ after initiating treatment with chemotherapeutic agents, antibody or immune therapies, targeted agents and glucocorticoids due to the rapid release of high amounts of intracellular components, which result in hyperkalemia, hyperphosphatemia, secondary hypocalcemia, hyperuricemia, and severe organ dysfunction [6]. Acute renal failure develops when the general compensation mechanisms for maintaining metabolic homeostasis fail. The acute renal failure is typically caused by obstructive urate nephropathy, triggered by uric acid precipitation in the tubular system [20].

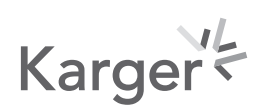


Table 3. Malignancies in which TLS prophylaxis is recommended due to the risk of TLS [2, 24, 25]

\begin{tabular}{|c|c|c|}
\hline Low TLS risk & Intermediate TLS risk & High TLS risk \\
\hline $\begin{array}{l}\text { Most solid tumors }[24,25] \\
\text { - Non-small cell lung cancer } \\
\text { - Breast cancer } \\
\text { - Ovarian cancer } \\
\text { - Vulvar cancer } \\
\text { - Prostate cancer } \\
\text { - Renal cell cancer } \\
\text { - Hepatocellular cancer } \\
\text { - Adenocarcinoma of the gastrointestinal } \\
\text { tract } \\
\text { - Malignancies } \\
\text { - Rhabdomyosarcoma } \\
\text { - Thymoma } \\
\text { CLL and Lc }<50 \times 10^{9} / \mathrm{L} \text { treated with } \\
\text { alkylating agents } \\
\text { AML and Lc }<25 \times 10^{9} / \mathrm{L} \text { and LDH increase } \\
\text { to }<2 \times \text { ULN } \\
\text { MM } \\
\text { CML } \\
\text { Indolent NHL } \\
\text { ALCL }\end{array}$ & $\begin{array}{l}\text { Solid tumors with high tumor burden, } \\
\text { advanced tumor stage, and high } \\
\text { chemosensitivity } \\
\text { - Small-cell lung } \\
\text { cancer } \\
\text { - Germ cell tumors } \\
\text { - Neuroblastoma } \\
\text { CLL treated with fludarabine, rituximab or } \\
\text { lenalidomide or venetoclax and LN }>5 \mathrm{~cm} \text { or } \\
\text { absolute lymphocyte count }>25 \times 10^{9} / \mathrm{L} \text { and } / \text { or } \\
\text { Lc }>50 \times 10^{9} / \mathrm{L} \\
\text { AML and Lc } 25-100 \times 10^{9} / \mathrm{L} \\
\text { AML and Lc }<25 \times 10^{9} / \mathrm{L} \text { and LDH increase to } \\
>2 \times \text { ULN } \\
\text { T-cell leukemia/lymphoma, diffuse large B-cell } \\
\text { lymphoma, and mantle cell lymphoma, each } \\
\text { with low tumor burden and elevated LDH and } \\
\text { ALL and Lc }<100 \times 10^{9} / \mathrm{L} \text { and LDH increase to } \\
<2 \times \text { ULN } \\
\text { Burkitt's lymphoma and LDH increase to }<2 \times \\
\text { ULN } \\
\text { Lymphoblastic lymphoma stage I/II and LDH } \\
\text { increase }<2 \times \text { ULN }\end{array}$ & $\begin{array}{l}\text { Malignancies with intermediary } \\
\text { risk and renal insufficiency } \\
\text { Malignancy with intermediary } \\
\text { risk and elevated serum } \\
\text { parameters uric acid, potassium, } \\
\text { and/or phosphate } \\
\text { CLL treated with venetoclax and } \\
\text { LN }>10 \mathrm{~cm} \text { or LN }>5 \mathrm{~cm} \text { absolute } \\
\text { lymphocyte count }>50 \times 10^{9} / \mathrm{L} \\
\text { and elevated uric acid } \\
\text { AML and Lc } 100 \times 10^{9} / \mathrm{L} \\
\text { T-cell leukemia/lymphoma, } \\
\text { diffuse large B-cell lymphoma, } \\
\text { and mantle cell lymphoma with } \\
\text { high tumor burden and LDH } \\
\text { increase }>2 \times \text { ULN } \\
\text { ALL and Lc }>100 \times 10^{9} / \mathrm{L} \text { and/or } \\
\text { LDH increase }>2 \times \text { ULN } \\
\text { Burkitt's lymphoma stage III/IV } \\
\text { and/or LDH increase }>2 \times \text { ULN } \\
\text { Burkitt leukemia } \\
\text { Lymphoblastic lymphoma stage } \\
\text { III/IV and/or LDH increase }>2 \times \\
\text { ULN }\end{array}$ \\
\hline
\end{tabular}

CML, chronic myeloid leukemia; MM, multiple myeloma; CLL, chronic lymphocytic leukemia; AML, acute myeloid leukemia; ALCL, anaplastic large cell lymphoma; ALL, acute lymphocytic leukemia; Lc, leukocytes; LN, lymph nodes; NHL, non-Hodgkin lymphoma.

\section{How Can the Risk of TLS Be Detected?}

In the development of TLS, a distinction is made between tumor-specific and tumor-independent risk factors $[3,4,6,20]$. Tumor-associated factors generally include tumors with a high proliferation rate, a large tumor load, and pronounced chemosensitivity (pediatric tumors, germ cell tumors, small-cell lung cancer), which favor the development of TLS. In particular, these include acute lymphoblastic leukemia and aggressive non-Hodgkin's lymphoma, such as Burkitt's lymphoma [21] (Table 3).

Markers for large-scale cell death include tumor and lymph nodes in sizes exceeding 10 $\mathrm{cm}$, leukocytosis ( $>500,000 / \mu \mathrm{L}$ ), $\mathrm{LDH}$ increases to over twice the reference range, as well as organ and bone marrow infiltration at the time of diagnosis. There are also predisposing tumor-independent factors, such as advanced age, pre-existing renal dysfunction, oliguria, anuria, hyperuricemia, dehydration, deviations from normal urine $\mathrm{pH}$ value (low $\mathrm{pH}$ value: risk of urate nephropathy; high $\mathrm{pH}$ value: risk of calcium phosphate precipitation [22]), and concomitant administration of potentially nephrotoxic drugs [6]. The use of these criteria to identify at-risk patients is the first step for managing TLS. According to Cairo et al. [3], a distinction is made between low-risk, intermediate-risk, and high-risk groups. Preventive measures are guided by the identified risk as described below.

\section{Karger'k}




\section{Which Prophylactic Measures Are Available?}

If a patient is at increased risk of developing TLS, the first priority is to prevent the onset of TLS [2]. Basic measures for patient monitoring include daily logging of fluid intake and output, daily weight checks and close laboratory controls, specifically for uric acid, potassium, calcium, creatinine, phosphate, blood glucose, LDH and INR value. In addition, medication lists should be carefully reviewed and the administration of nephrotoxic substances should be avoided.

Regardless of the risk group, any therapeutic measures must be based on adequate intravenous patient hydration with a fluid supply of 2-4 L/day. The recommendations for selecting intravenous fluids vary [4]. Both sodium chloride and Ringer's lactate can be used. In patients with comorbidities, such as diabetes mellitus or heart failure, hydration should be monitored to avoid pulmonary edema.

The aim is to increase urinary excretion with a subsequent dilution effect of dissolved uric acid in the renal tubular system. Loop diuretics are used for forced diuresis, as they have a potent diuretic effect and flush out potassium. The target urine quantity is $80-100 \mathrm{~mL}$ per hour [6]. Hydration should be continued as long as signs of tumor cell death are evident $[2,9,10,22]$.

\section{Which Therapeutic Measures Are Available for Treating Clinical TLS?}

Hyperuricemia

Treatment with the urostatic drug allopurinol should be started $24-48 \mathrm{~h}$ before initiating chemotherapy. The recommended dose is $300-600 \mathrm{mg}$ orally. Allopurinol intervenes in the DNA catabolism, where it competitively and reversibly inhibits the enzyme xanthine oxidase to prevent the degradation of hypoxanthine and xanthine nucleic acids. As a result, a smaller quantity of poorly soluble uric acid is formed and the water-soluble xanthine and hypoxanthine can be excreted through the kidneys. The dosage should be reduced in patients with kidney disease [23]. The advantages of this therapeutic measure are low cost and oral administration, while its disadvantage is a delayed onset of action by $24-72 \mathrm{~h}$. As a result, allopurinol can only be used to a limited extent in the presence of high uric acid levels ( $\geq 476 \mu \mathrm{mol} / \mathrm{L}$ ). The increased xanthine and hypoxanthine volumes also make it necessary to consider the risk of xanthine-induced renal failure as a differential diagnosis $[4,7,23]$.

In contrast to allopurinol, rasburicase causes a rapid drop in uric acid without delay. The recombinant enzyme cleaves the uric acid into allantoin, a significantly more water-soluble nucleic acid. Further advantages of this drug include rapid onset and good tolerability $[4,6]$. In both the study by Cortes et al. [26] and the meta-analysis by Lopez-Olivo et al. [27], rasburicase was found to be more effective for reducing uric acid levels. However, this had no effect on a better outcome in terms of clinically manifest TLS. The authorized dosage scheme is $0.15-0.20 \mathrm{mg} / \mathrm{kg} /$ day as a single intravenous infusion for 5-7 days. Some studies have shown that a weight-independent single dose of rasburicase had the same effect as extended therapy in most patients [28-30]. The use of rasburicase is contraindicated in the presence of known glucose- 6 phosphate dehydrogenase deficiency since severe hemolytic anemia may develop as a consequence of hydrogen peroxide formation $[6,31]$.

\section{Hyperkalemia}

Hyperkalemia remains the most dangerous electrolyte abnormality in the context of TLS due to the risk of life-threatening cardiac arrhythmia [6]. Depending on the severity, a number of therapeutic measures are available [32]. An increase of serum potassium $>7 \mathrm{mmol} / \mathrm{L} \mathrm{repre-}$ sents a medical emergency and requires immediate action. The intravenous administration of insulin and glucose or $\beta-2$ mimetics cause an intracellular potassium shift, while calcium gluconate leads to the additional stabilization of cardiac membranes. However, this frequently only achieves a temporary effect, and renal replacement therapy is needed.

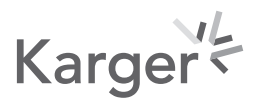


Hyperphosphatemia/Hypocalcemia

Any existing hyperphosphatemia should be corrected. It is best to treat moderate hyperphosphatemia with a low-phosphate diet and phosphate binders [32]. Since electrolyte imbalances can be difficult to manage with drug therapy in spite of all measures, renal replacement therapy should therefore be prescribed in the majority of cases [6, 22, 33].

Hyperphosphatemia causes secondary hypocalcemia, which reinforces cardiac arrhythmia tendencies and can also cause tetany, muscle cramps, and seizures. Due to the risk of calcium phosphate deposits, it is best not to treat asymptomatic hypocalcemia, while manifest hypocalcemia should be treated with the lowest possible calcium gluconate dose until the symptoms abate $[6,22]$.

\section{Indication of Renal Replacement Therapy}

In spite of the best prevention and therapy, some patients develop serum electrolyte imbalances that cannot be treated conservatively as well as acute renal failure. Dialysis is indicated in these cases [6]. The chances of full renal function recovery are good, provided the renal replacement therapy is initiated early and leads to an adequate reduction of uric acid and phosphate levels.

Absolute dialysis indications are severe oliguria or anuria, therapy-resistant hyperkalemia and hyperphosphatemia, and symptomatic hyperphosphatemia-induced hypocalcemia $[7,22,34]$.

\section{Conclusion}

Spontaneous TLS is a rare hemato-oncological emergency situation. Patients with elevated tumor-associated and individual risk should be identified as such and must be closely monitored for clinical and laboratory parameters [14]. This allows for the early initiation of preventive measures and can have a positive influence on the clinical course. Manifest TLS, on the other hand, generally requires intensive therapy.

\section{Statement of Ethics}

For this paper, the authors did not conduct any studies in humans or animals. The ethical guidelines for the studies listed apply to the respective studies. The patient has given his informed consent to the publication of the present case report including the publication of images.

\section{Conflict of Interest Statement}

The authors state that there is no conflict of interest.

\section{Funding Sources}

The authors received no financial support for this contribution. 


\section{Case Reports in Oncology}

\begin{tabular}{l|l}
\hline Case Rep Oncol 2020;13:1116-1124 \\
\hline DOI: 10.1159/000509643 & $\begin{array}{l}\text { @ 2020 The Author(s). Published by S. Karger AG, Basel } \\
\text { www.karger.com/cro }\end{array}$ \\
\hline
\end{tabular}

Wesemüller/Taverna: Tumor Lysis Syndrome

\section{Author Contributions}

The corresponding author wrote the entire article, researched the literature, evaluated this literature in the discussion, and wrote the tables. The co-author has read the article and provided suggestions for correction. No other persons were involved.

\section{References}

1 Inauen R, Taverna C, Benz R. Syndrome de lyse tumorale. Forum Med Suisse. 2013;13(34):648-51.

2 Cairo MS, Coiffier B, Reiter A, Younes A; TLS Expert Panel. Recommendations for the evaluation of risk and prophylaxis of tumour lysis syndrome (TLS) in adults and children with malignant diseases: an expert TLS panel consensus. Br J Haematol. 2010;149(4):578-86.

3 Cairo MS, Bishop M. Tumour lysis syndrome: new therapeutic strategies and classification. Br J Haematol. 2004;127(1):3-11.

4 Coiffier B, Altman A, Pui CH, Younes A, Cairo MS. Guidelines for the management of pediatric and adult tumor lysis syndrome: an evidence-based review. J Clin Oncol. 2008;26(16):2767-78.

5 Kollathodi SB, Parameswaran KK, Madhavan L, Kuruvilla S. Hematological malignancies presenting as spontaneous tumor lysis syndrome: A case series. J Family Med Prim Care. 2018;7(5):1116-9.

6 Mirrakhimov AE, Voore P, Khan M, Ali AM. Tumor lysis syndrome. A clinical review. World J Crit Care Med. 2015;4(2):130-8.

7 Kekre N, Djordjevic B, Touchie C. Spontaneous tumour lysis syndrome. CMAJ. 2012;184(8):913-6.

8 Tufan A, Unal N, Koca E, Onal I, Aksu S, Haznedaroglu I. Spontaneous tumor lysis syndrome in a patient with diffuse large B cell lymphoma and Richter syndrome. Ann Hematol. 2006;85(3):183-4.

9 Huhn D, Henze G. Tumorlysesyndrom. Ein Leitfaden für die Klinik. Stuttgart:Thieme Verlag; 2002.

10 Roque W, Rehman A, Suero-Abreu GA, Danek BA, Colao J, Fayngersh A, et al. Spontaneous tumor lysis syndrome in T-cell malignancy: two case reports. Stem Cell Investig. 2019;6:24.

11 Ali AM, Barbaryan A, Zdunek T, Khan M, Voore P, Mirrakhimov AE. Spontaneous tumor lysis syndrome in a patient with cholangiocarcinoma. J Gastrointest Oncol. 2014;5(2):E46-9.

12 Myint PT, Butt HW, Alrifai T, Mari C. Spontaneous tumor lysis syndrome secondary to small-cell neuroendocrine carcinoma of unknown origin: a rare case report and literature review. Case Rep Oncological Med. 2019; 3:1-6.

13 Dhakal P, Rai MP, Thrasher M, Sharma M. Spontaneous tumour lysis syndrome in small cell lung cancer: a rare phenomenon. BMJ Case Rep. 2018;bcr2018224512.

14 Gangireddy M, Shrimanker I, Nookala VK, Peroutka KA. Spontaneous Tumor Lysis Syndrome in Diffuse Large B-cell Lymphoma: Early Diagnosis and Management. Cureus. 2019;11(5):e4679.

15 Gbaguidi X, Goodrich L, Roca F, Suel P, Chassagne P. Bulky solid tumors in elderly adults: beware of spontaneous tumor lysis syndrome. J Am Geriatr Soc. 2016;64(1):235-7.

16 Tosi P, Barosi G, Lazzaro C, Liso V, Marchetti M, Morra E, et al. Consensus conference on the management of tumor lysis syndrome. Haematologica. 2008;93(12):1877-85.

17 Belay Y, Yirdaw K, Enawgaw B. Tumor lysis syndrome in patients with haematological malignancies. J Oncol. 2017;2017:9684909.

18 Vodopivec DM, Rubio JE, A Fornoni, Lenz O. An unusual presentation of tumor lysis syndrome in a patient with advanced gastric adenocarcinoma: case report and literature review. Case Rep Med. 2012;2012:468452 pages.

19 Parsi M, Rai M, Clay C. You can't always blame the chemo: a rare case of spontaneous tumor lysis syndrome in a patient with invasive ductal cell carcinoma of the breast. Cureus. 2019;11(11):e6186.

20 Howard SC, Jones DP, Pui CH. The tumor lysis syndrome. N Engl J Med. 2011;364(19):1844-54.

21 Jasek AM, Day HJ. Acute spontaneous tumor lysis syndrome. Am J Hematol. 1994;47(2):129-31.

22 Nusshag C, Fink S, Zeier M. Das Tumorlysesyndrom. Nephrologe. 2016;11(1):6-13.

23 Alakel N, Middeke JM, Schetelig J, Bornhäuser M. Prevention and treatment of tumor lysis syndrome, and the efficacy and role of rasburicase. Onco Targets Ther. 2017;10:597-605.

24 Mirrakhimov AE, Ali AM, Khan M, Barbaryan A. Tumor Lysis Syndrome in Solid Tumors: An up to Date Review of the Literature. Rare Tumors. 2014;6(2):5389.

25 Ignaszewski M, Kohlitz P. Treatment-naïve spontaneous tumor lysis syndrome in metastatic prostate adenocarcinoma: An unusual suspect. Am J Emerg Med. 2017;35(9):1384.e1-1384.e2.

26 Cortes J, Moore JO, Maziarz RT, Wetzler M, Craig M, Matous J, et al. Control of plasma uric acid in adults at risk for tumor lysis syndrome: efficacy and safety of rasburicase alone and rasburicase followed by allopurinol compared with allopurinol alone - results of a multicenter phase III study. J Clin Oncol. 2010;28(27):4207-13.

27 Lopez-Olivo MA, Pratt G, Palla SL, Salahudeen A. Rasburicase in tumor lysis syndrome of the adult: a systematic review and meta-analysis. Am J Kidney Dis. 2013;62(3):481-92.

28 Campara M, Shord SS, Haaf CM. Single-dose rasburicase for tumour lysis syndrome in adults: weight-based approach. J Clin Pharm Ther. 2009;34(2):207-13. 
29 McBride A, Lathon SC, Boehmer L, Augustin KM, Butler SK, Westervelt P. Comparative evaluation of single fixed dosing and weight-based dosing of rasburicase for tumor lysis syndrome. Pharmacotherapy. 2013; 33(3):295-303.

30 Reeves DJ, Bestul DJ. Evaluation of a single fixed dose of rasburicase $7.5 \mathrm{mg}$ for the treatment of hyperuricemia in adults with cancer. Pharmacotherapy. 2008;28(6):685-90.

31 Sonbol MB, Yadav H, Vaidya R, Rana V, Witzig TE. Methemoglobinemia and hemolysis in a patient with G6PD deficiency treated with rasburicase. Am J Hematol. 2013;88(2):152-4

32 Maxwell AP, Linden K, O'Donnell S, Hamilton PK, McVeigh GE. Management of hyperkalaemia. J R Coll Physicians Edinb. 2013;43(3):246-51.

33 Malberti F. Hyperphosphataemia: treatment options. Drugs. 2013;73(7):673-88.

34 Larson RA. Tumor lysis syndrome: prevention and treatment. UpToDate. 2019;1-22. 